\title{
Las intervenciones del obispo Marcelino Siuri en la catedral de Córdoba
}

\author{
Renovations of Bishop Marcelino Siuri in the \\ Cathedral of Córdoba
}

\author{
Francisco Manuel PÉREZ GARCÍA \\ Universidad de Córdoba
}

Recibido: 21-I-2015 / Aceptado: 21-IV-2015

Resumen: El presente trabajo muestra la transformación que sufrió el templo catedralicio de Córdoba durante el siglo XVIII, recopilando y aportando documentación que permite entender la magnitud de la intervención y el papel desempeñado por Marcelino Siuri. Por un lado, con importantes aportes económicos tanto del prelado como del cabildo catedralicio, se concluyó el abovedamiento de estética barroca y por otro lado, bajo el patrocinio del obispo, se llevó a cabo la transformación de la capilla del baptisterio configurada por el único retablo fingido de la catedral.

Palabras clave: Marcelino Siuri, Catedral de Córdoba, Transformación espacial, Bóvedas barrocas, Capilla del baptisterio, Pila bautismal, Retablo fingido, Pedro Moreno.

ABSTRACT: After the compilation of many documents that help us to understand the importance of the renovation and also the role of Bishop Marcelino Siuri, this article shows how the Cathedral of Córdoba underwent a transformation during the 18th Century. On the one hand, the prelate and canonry of the Cathedral made a big investment of money to finish the baroque vaulting of the building; and on the other hand, the Bishop patronised the transformation of the baptistery chapel which shelters the only trompe l'oeil altarpiece of the Cathedral.

Keys words: Marcelino Siuri, Córdoba catedral, Spatial transformation, Baroque vaults, Baptistery chapel, Baptismal font, Trompe l'oeil altarpiece, Pedro Moreno.

Las catedrales son edificaciones cuya estructura y contenido se han gestado de manera progresiva a lo largo de su historia. Desde su construcción, en ellas quedan plasmadas las huellas de las diversas etapas históricas por las que atraviesan. Quedan impregnadas de las necesidades de la liturgia eclesiástica, de las mentalidades de la socie- dad, de las corrientes estéticas e incluso de otros aspectos más subjetivos relacionados con los intereses de obispos y cabildos catedralicios ${ }^{1}$. En definitiva, cada etapa histórica trae consigo transformaciones que permiten

${ }^{1}$ E. MORAIS VALLEJO, “La transformación barroca del interior de la catedral de León. Una idea con una larga gestación", De Arte, 5, 2006, p. 133. 
que estos edificios se adapten a las nuevas necesidades. Las causas y las modificaciones a las que son sometidas son de muy diversa índole. Por un lado, las causas están regidas, en la mayoría de los casos, por la necesidad de mantener de manera óptima el estado de conservación, ya que son los emblemas de las diócesis y representan el poder episcopal. No obstante, ésta no es la principal ni única motivación que conlleva una intervención en ellas, ya que los sucesivos cambios de la liturgia traen consigo una adaptación de los espacios, al igual que las nuevas corrientes estéticas y de pensamiento conllevan una transformación artística y estilística, y los intereses de obispos y cabildos desembocan en importantes modificaciones. Es por todo ello que los edificios catedralicios están sometidos a constantes adaptaciones a fin de que todos los aspectos indicados se vean conjugados tanto en sus estructuras como en su exornación ${ }^{2}$. Las modificaciones son muy diversas también, ya que pueden basarse en la rehabilitación del edificio, en la sustitución de elementos anticuados, o por el contrario, en la construcción de añadidos o en la eliminación de elementos tanto estructurales como decorativos. A su vez, las modificaciones conllevan el desarrollo de nuevos modelos estilísticos acordes con las corrientes de pensamiento. Las catedrales son símbolos de poder y como tales se convierten en modelos a seguir en determinadas etapas históricas.

El barroco supuso un período en el que las modificaciones de los templos catedralicios fueron muy frecuentes ya que la situación económica y las nuevas corrientes estéticas imposibilitaban la destrucción de las edificaciones heredadas y la construcción de nuevos edificios. Por ello, las intervenciones no supusieron nada más que una transformación espacial acorde a los nuevos sistemas de valores vinculados a su contex-

\footnotetext{
${ }^{2}$ En este sentido destaca el trabajo de J. J. MARTÍN GONZÁLEZ, "La catedral como núcleo promotor del barroco español", I Congrego Internacional do Barroco, vol. II, Porto, 1991, pp. 4-16.
}

to artístico y cultural ${ }^{3}$. Al contrario de otras etapas históricas, durante el barroco las intervenciones se realizaron de manera respetuosa y primaba el interés por la conservación del edificio heredado. No obstante, las reformas no implicaban una modificación estructural importante, pero el resultado conllevaba la percepción de una edificación nueva cobijada en la estructura de la anterior, es decir, se extraía la mayor rentabilidad de los viejos templos a fin de que éstos albergaran en su interior la concepción ideológica, estética y funcional adaptada a los nuevos tiempos ${ }^{4}$.

La catedral de Córdoba es un templo ubicado dentro de un recinto islámico; por ello se trata de un ejemplo único. Desde la consagración del edificio como templo cristiano a comienzos del siglo XIII se han llevado a cabo multitud de intervenciones arquitectónicas y ornamentales a fin de adaptar el espacio a sus nuevas funciones. Se construyeron capillas en el interior, se cerraron todos los arcos que daban acceso desde el patio con capillas y canceles, se transformó un espacio para albergar la capilla mayor primigenia, en uso hasta 1607, cuando se construyó la actual capilla mayor, el crucero y el coro. Ésta última obra implicó la mayor transformación espacial del recinto regida por la eliminación de parte de la estructura original del edificio para albergar en su lugar una nueva construcción. En este caso, la adaptación del edificio no se puede equiparar al resto de templos, ya que el recinto que lo configura no era un construcción catedralicia. Por lo tanto, experimentó a lo largo de la historia importantes mutaciones estructurales a fin de adaptarlo a sus nuevas funciones como templo cristiano. Es por ello, que el respeto por la fábrica heredada observado en otros ejemplos catedralicios en

${ }^{3}$ A. TOVAR MARTÍN, El arte barroco. Arquitectura. Madrid, 1999, p. 115; ÍDEM, Los siglos del barroco. Arquitectura. Madrid, 1997, p. 60.

${ }^{4}$ A. ROSENDE VALDÉS, "La modificación de las tipologías tradicionales en el mundo moderno: la ampliación y reforma de las catedrales gallegas" En Las catedrales españolas en la Edad Moderna, Madrid, 2001, p. 52. 
este caso no se aprecia, dada la superposición ideológica y la reutilización estructural de la misma. No obstante, en ella se aprecian las huellas que las diversas etapas históricas han dejado, en ocasiones creando fuertes transformaciones y en otras respetando, en cierta medida, su integridad.

A comienzos del siglo XVIII se emprendieron labores de rehabilitación de las techumbres que desembocaron en la sustitución de la armadura islámica, situando en su lugar bóvedas encamonadas. La intervención no provocó una transformación fuerte a nivel estructural, sin embargo trajo consigo una concepción espacial nueva acorde con la estética del momento. En el transcurso de estas obras la silla episcopal quedó vacante y fue ocupada a finales de 1717 por el obispo Marcelino Siuri (Fig. 1) $)^{5}$. A su llegada, la diócesis cordobesa se encontraba inmersa en una situación económica complicada que había provocado la paralización de las referidas obras. Será a partir de entonces cuando el prelado, junto con el cabildo catedralicio, intervengan de manera activa. Así, se reanudaron las labores y llegaron a su fin a lo largo del año 1720. A su vez, el templo, debido a diversas vicisitudes, carecía de una capilla bautismal acorde a la dignidad del mismo. Siuri patrocinará la transformación de la referida capilla a fin de adaptarla a las nuevas

\footnotetext{
${ }^{5}$ Don Marcelino Siuri Navarro nació el 26 de abril de 1654. Junto a sus padres se trasladó hasta Valencia donde comenzó su formación académica basada en el estudio de la gramática, filosofía, artes liberales y teología. Alcanzó el grado de doctor en la Universidad de Valencia donde desempeñó su carrera como docente durante seis años consecutivos. En 1681 fue nombrado Pavorde de la Santa Iglesia Metropolitana de Valencia quedando a cargo de la Cátedra de teología durante 27 años. En 1708 por mandato del rey Felipe V es nombrado obispo de Orense donde permaneció hasta 1717 cuando fue trasladado hasta la diócesis cordobesa. En ella continuó hasta el año 1731 cuando sus constantes problemas de salud se agravaron hasta acabar con su vida. J. GÓMEZ BRAVO, Catálogo de los obispos de Córdoba, y breve noticia histórica de su Iglesia Catedral y Obispado, Córdoba, 1778; F. SEGUER, Vida ejemplar del Ilmo. Sr. don Marcelino Siuri, pavorde de la Santa Metropolitana Iglesia de Valencia, Obispado de Orense y después de Córdoba, Córdoba, 1775 .
}

corrientes estéticas. El resultado fue el único retablo fingido de la catedral cordobesa.

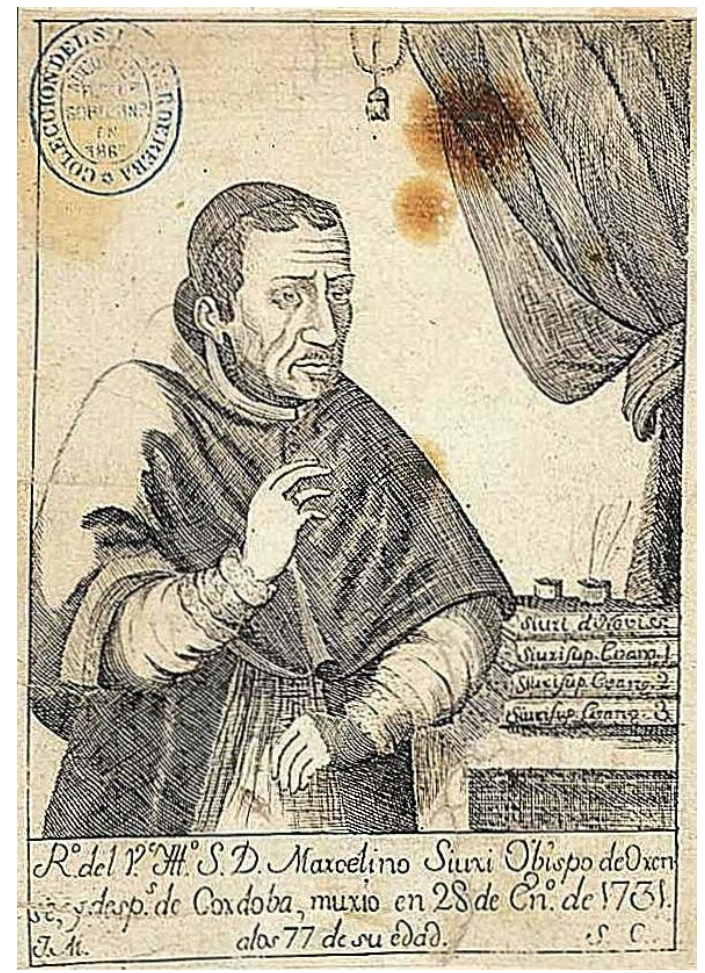

- Fig. 1. Grabado de don Marcelino Siuri Navarro. http://www.bne.es

\section{BÓVEDAS BARROCAS}

A comienzos del siglo XVIII, el recinto catedralicio conservaba las techumbres originales, a excepción del espacio que ocupó la primitiva capilla mayor, el crucero, el coro y la capilla mayor de la actual catedral y la nave axial de la mezquita fundacional de Abd-al Rahman I en la que fray Diego de Mardones construyó a comienzos de 1617 una cúpula en el primer tramo; fray Alonso de Medina y Salizanes culminó con bóvedas barrocas el resto de la nave entre 1679 y $1682^{6}$. Consistían en armaduras de madera decoradas a base de policromía y talladas en determinadas zonas. Debido al transcurso del tiempo, sobre todo ante los problemas

${ }^{6}$ M. A. JORDANO BARBUDO, "La intervención de los obispos Mardones y Salizanes en la nave central de Abd al- Rahman I en la mezquita-catedral de Córdoba", Ámbitos, no 24, 2010, pp. 13-21. 
de humedad, se encontraban en un estado deplorable amenazando ruina en diversas partes del edificio ${ }^{7}$. Además, una vez cegadas las arcadas que daban acceso a través del patio, la única iluminación del templo procedía del crucero de la catedral, de los lucernarios correspondientes a la ampliación de Al-Hakam II y de la cúpula construida a comienzos del siglo XVIII por el obispo Mardones ${ }^{8}$. Todo ello dio lugar a un recinto cerrado al que se debía de dotar de la iluminación necesaria. Estas fueron las causas iniciales que conllevaron la realización de este gran proyecto. Sin embargo, además de estas había otras causas que impulsaron la intervención en las cubiertas aprovechando su deteriorado estado. Desde el punto de vista artístico esta transformación buscó un cambio en la concepción espacial del edificio, logrado por la sustitución de las armaduras por bóvedas encamonadas, por la construcción de lucernarios que iluminaron la zona correspondiente a la ampliación de Almanzor y finalmente por el enjalbegado de todos los paramentos del interior. El resultado de todo ello fue un templo con unos valores estéticos y una concepción espacial adaptados a las nuevas corrientes artísticas del barroco. A su vez, la participación del cabildo y de los diversos obispos a lo largo de todo su desarrollo muestra la intencionalidad evidente de que su paso por el obispado quedara reflejado en el edificio. De este modo, don Marcelino Siuri, junto con el cabildo, decidieron invertir un importante caudal de dinero con el fin de acelerar la finalización de este gran proyecto que concluyó con una transformación material del templo y con una metamorfosis visual donde la mono-

${ }^{7}$ M. NIETO CUMPLIDO, La catedral de Córdoba. Córdoba, 2007, p. 250; Realiza una fuerte crítica a la construcción de las bóvedas barrocas L. M. RAMÍREZ Y DE LAS CASAS DEZA, Descripción de la catedral de Córdoba, Córdoba, 1866, pp. 129-130.

${ }^{8}$ El cabildo celebrado el 26 de octubre de 1718 propone el cerramiento de los arcos que aún permanecían abiertos a fin de otorgar mayor dignidad al templo. Archivo de la Catedral de Córdoba (en adelante ACCO), Actas Capitulares, libro 71, año 1718. cromía de los paramentos y el aumento de altura de las bóvedas hacían que, gracias al nuevo sistema de iluminación, la luz invadiera todo el espacio logrando la persuasión y la teatralidad que caracterizaba al barroco.

Las obras de la nueva cubierta del templo comienzan el 11 de septiembre de 1711 con la revisión y reconstrucción de los tejados de la capilla y nave de Nuestra Señora de Villaviciosa9. En el transcurso de los años las obras se fueron desarrollando tal y como se puede observar por los constantes libramientos y donaciones que quedan recogidos en las cuentas de fábrica del templo ${ }^{10}$. A su vez, el cabildo llevó a cabo diversas iniciativas con las que obtener un aporte económico para la prosecución de las obras ${ }^{11}$. Cuando

${ }^{9}$ ACCO, Cuentas de fábrica, libro 4.011, año 17081713.

${ }^{10}$ En el año de 1711, se realizan cuatro libramientos para comprar los materiales necesarios para las obras que se iban a emprender, sumando una cuantía total de 2.156 reales y 8 maravedíes de vellón. En el transcurso de los dos años siguientes, por parte del obispo fray Juan de Bonilla, se otorgaron 21.730 reales y 13 maravedíes de vellón distribuidos en 22 libramientos para la compra de materiales (canales ordinarios, redoblones vidriados, ladrillos, cal, yeso, y tejas). Ibídem. Desde 1714 hasta 1716 se libraron 4.055 reales de vellón, empleados en materiales de construcción y en las tareas de fundición de varios canales de plomo y estaño. Asimismo, por parte del obispo don Francisco Solis Hervás, se libraron 10.099 reales de vellón durante todo el periodo que permaneció al cargo de la diócesis cordobesa. Ibídem, libro 4.012, año 1713-1716. Desde el comienzo de las obras se fueron sucedieron diversas donaciones. Don Gregorio Macías Soler, canónigo de la Santa Iglesia y administrador del caudal de reparo de obras, donó los 30.000 reales de vellón que le correspondían tras la realización de las cuentas correspondientes de la mesa capitular. Ibídem, libro 4.011, año 1708-1713. En 1717, don Alonso de la Nava, canónigo de esta Santa Iglesia, entregó 25.000 reales de vellón para las nuevas bóvedas que correspondían con la capilla del sagrario. Ibídem, libro 4.013, año 1717 .

${ }^{11}$ El 20 de julio de 1714 se recoge una referencia en actas capitulares respecto a los cambios realizados en el sistema de iluminación durante la celebración de las noches de la Natividad del Señor. Se pasó de hachas de cera a faroles dado el coste que conllevaban y los muchos perjuicios que ocasionaban las mencionadas hachas. Ibídem, Actas Capitulares, libro 69, año 1712-1714. Asimismo, en el año 1717 el cabildo catedralicio otorgó 
Marcelino Siuri se hizo cargo de la diócesis cordobesa los trabajos de abovedamiento estaban muy atrasados debido a la escasez de medios económicos a pesar de las donaciones, limosnas y medidas llevadas a cabo por el cabildo. Ante la complicada situación no cesan las donaciones ${ }^{12}$. No obstante, la medida más importante fue realizada por el cabildo al ofrecer 16.000 ducados del caudal de obras pías para redimir el censo que recaía sobre la catedral y proseguir las obras con el dinero restante ${ }^{13}$. Se solicitó licencia a Siuri para autorizar la transacción y se otorgaron las escrituras ante don Diego Juan de Pineda el 18 de marzo de $1718^{14}$. Sin embargo, dados los altos costes que las obras estaban conllevando, Marcelino Siuri decidió sufragar el referido censo entregando 12.000 ducados de su propio caudal ${ }^{15}$. Con este significativo aporte otorgado por el cabildo las labores de las cubiertas, que se habían pro-

licencia al obrero mayor para que tomase 2.000 ducados a censo sobre los bienes de la fábrica de cualquier depósito de la catedral para este mismo fin. Ibídem, Libro 71, año 1717.

${ }^{12}$ Se realizaron varias donaciones: por un lado, don Alonso de la Nava vuelve a participar directamente en las obras con un aporte de 402 pesos y medio escudos de plata (208.692 maravedíes de vellón). Ibídem, Cuentas de fábrica, libro 4.014, año 1718-1719. Y por otro lado se verifican dos donaciones del obispo de Almería y del que fue canónigo y obrero de la catedral de Córdoba, don Jerónimo del Valle, por cuyo vínculo entregó 400 pesos escudos de plata (207.400 maravedíes de vellón) y 1.000 reales de vellón años más tarde. Ibídem, libro 4.015, año 1720-1722. El 22 de enero de 1720 se realizó otra donación de 3.100 reales de vellón entregados por don Alonso de la Nava, don Juan Gómez Bravo y por don Marcelino Siuri. Ibídem, Libro 4.014, fecha 1718-1719.

${ }^{13}$ Archivo Histórico Provincial de Córdoba (en adelante AHPCO), Protocolos Notariales, caja 15.991P, fol. $474 \mathrm{r} .-487 \mathrm{v}$.

${ }^{14}$ Íbidem.

${ }^{15}$ J. GÓMEZ BRAVO, Op.cit., p. 772; F. SEGUER, Op.cit., p. 80. La donación realizada por don Marcelino Siuri no se hizo efectiva hasta después de su muerte tal y como se recoge en su testamento póstumo. En él sus albaceas testamentarios cumplen con el legado que el prelado no pudo hacer en vida. AHPCO, Protocolos Notariales, caja 16.004P, fol. 554 r-565 v.; AHPCO, Protocolos Notariales, caja 15.991P, fol. 474 r. $-487 \mathrm{v}$. longado a lo largo de 9 años, concluyeron a finales de 1720. Durante el transcurso de los trabajos queda patente la preocupación por concluir las obras de los tres pontífices que ocuparon la silla episcopal, fray Juan de Bonilla, Francisco de Solís Hervás y Marcelino Siuri, al igual que la del cabildo, sin olvidar las continuas donaciones por parte de varios canónigos, entre los que destacó don Alonso de la Nava ${ }^{16}$.

A partir de 1720 la imagen del edificio cambió, se retiraron las armaduras de madera y se recrecieron los muros sobre las arquerías 1,20 m para trazar las bóvedas y buscar una solución técnica a los desagües ${ }^{17}$. Se construyeron en su lugar bóvedas encamonadas de yeso sostenidas por ilusorios arcos fajones que caen sobre fingidas ménsulas barrocas. Además, por encima del armazón de madera que sustenta las bóvedas, se construyeron otros armazones para la creación de los lucernarios ubicados en la ampliación de Almanzor. Éstos se sitúan en los extremos de las naves y cobijan dobles ventanas enfrentadas (Fig.2) ${ }^{18}$. A pesar de tratarse de lucernarios de dimensiones reducidas, al adaptarse al ancho de las naves, permitieron obtener iluminación natural. La conjunción de la luz con la mayor altura de las bóvedas y con la monocromía de los paramentos conllevó la mayor transformación espacial del recinto tras la construcción de la actual capilla mayor. Cambió la concepción del templo otorgándole una identidad nueva en la que la

\footnotetext{
${ }^{16}$ Para profundizar en los mecenas y el mecenazgo desarrollado durante el siglo XVIII se puede consultar el estudio de J.J. LÓPEZ-GUADALUPE MUÑOZ, "El mecenazgo artístico en la Granada del siglo XVIII. La financiación del arte religioso", en Poder civil, Iglesia y Sociedad en la Edad Moderna. Granada, 2006, pp. 359-398.

${ }^{17}$ M. NIETO CUMPLIDO, Op.cit., pp. 74 y 113; El aumento en altura de las techumbres se puede apreciar en el paramento liso que corona el muro norte de la catedral que da acceso al interior del templo desde el patio de los naranjos.

${ }^{18}$ A. GONZÁLEZ CAPITEL, "La catedral de Córdoba. Transformación cristiana de la mezquita", Arquitectura, no 256, 1985, pp. 44-45; M. NIETO CUMPLIDO, Op.cit., p. 307.
} 
percepción, el juego de las luces y la monumentalidad eran los elementos definitorios que a partir de entonces marcaron la esencia del nuevo recinto catedralicio (Fig. 3).

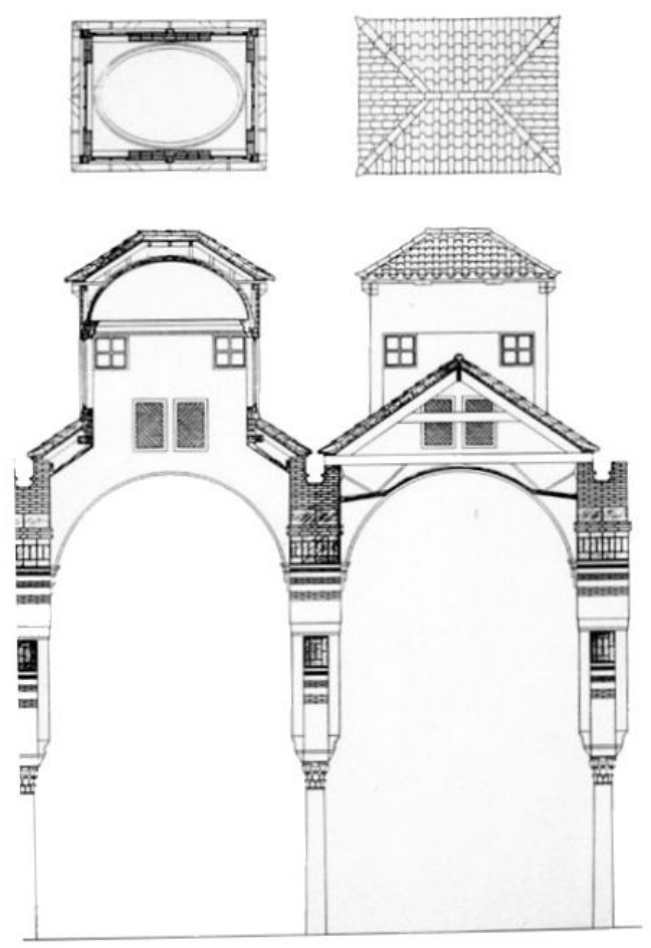

- Fig. 2. Sección de los lucernarios barrocos. http:// otraarquitecturaesposible.blogspot.com.es

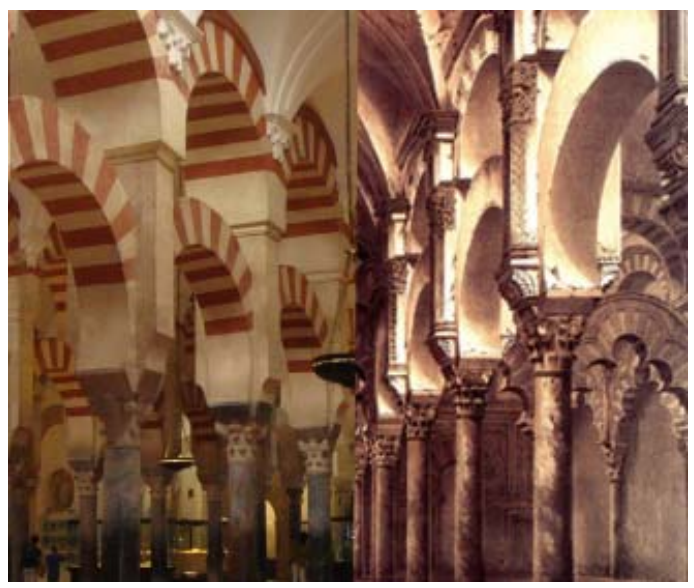

- Fig. 3. Arcadas de la catedral de Córdoba. A la izquierda con la bicromía actual y a la derecha enjalbegadas tras la intervención del siglo XVIII. http://otraarquitecturaesposible.blogspot.com.es y foto del autor.
La intervención, llevada a cabo durante casi una década, nos muestra que se buscaba crear una catedral cuya estética estuviera en consonancia con las nuevas corrientes impuestas por el barroco. Ello trajo consigo que se eliminara uno de los elementos definitorios del edificio: las armaduras. A lo largo de la dilatada historia de la catedral de Córdoba, las sucesivas intervenciones han mostrado respeto por la estructura islámica, con excepción de la capilla mayor, el crucero y el coro, ya que su construcción conllevó la aniquilación de parte de la antigua aljama ${ }^{19}$. No obstante, en el trasaltar se puede observar que existe una perfecta imbricación de los elementos renacentistas e islámicos. En él se sitúan relieves de la pasión de Cristo delimitados por arcadas de medio punto decoradas con la tradicional bicromía blanca y ocre $^{20}$. Dada la envergadura de las obras y el gran esfuerzo que conllevaron se podría haber prescindido de esas arcadas construyendo un nuevo sistema de sustentación y un nuevo programa ornamental acorde con los gustos del siglo XVI. Esta tendencia de unión de las nuevas corrientes estéticas con los vestigios del pasado tiene otro ejemplo en la decoración de la capilla del Sagrario, realizada por Cesar Arbasia, en la que se cubren las arcadas y los paramentos con pinturas murales basadas en escenas de todos los mártires cristianos y escenas y atributos de la pasión de Cristo. Dicha intervención reivindica la transformación espacial sin conllevar una aniquilación estructural del edificio pese a que ello en ocasiones fue im-

${ }^{19}$ M. NIETO CUMPLIDO, Op.cit., pp. 497-540. Dada la envergadura de las obras de la nueva capilla mayor, del crucero y del coro es imposible tratarlas en este trabajo sin perder el hilo conductor del mismo. Es por ello que se aconseja esta bibliografía como ampliación de la información aportada.

${ }^{20}$ Ibídem, p. 509; Para profundizar en el programa iconográfico e iconológico del crucero renacentista de la catedral de Córdoba ver F. MORENO CUADRO, “El crucero de la catedral de Córdoba: estudio iconográfico e iconológico", Cuadernos de Arte e Iconografía, tomo XVI, no 31, primer semestre de 2007, p. 297. 
posible de conseguir dada la naturaleza del mismo $^{21}$.

La intervención de Siuri en el proceso constructivo de las cubiertas no trajo consigo ninguna modificación respecto al proyecto inicial, ya que se trataba de una obra que había comenzado una década antes y se encontraba paralizada por falta de caudal y no porque hubiera surgido ningún problema constructivo que requiriera modificaciones. A su vez, el aporte donado por Siuri fue destinado al saneamiento económico del templo, eliminando el censo de poco mas de 11.000 ducados que recaía sobre él. Por lo tanto, el proyecto fue continuado y llevado a su fin por la suma de 16.000 ducados entregados por el cabildo. Se trató de una labor de patrocinio económico llevado a cabo de igual manera desde la silla episcopal como del cabildo catedralicio. Ambos eran los principales interesados en concluir la obra de cubrimiento, ya que con ella se dio una nueva identidad al templo y ambos patrocinadores se adjudicaron el final de tan importante obra de manera que sus huellas quedaron impresas en el edificio. Para el prelado esto era de vital importancia, ya que de este modo Siuri intentó equipararse al cardenal Salazar. Por un lado, para evitar quedar ensombrecido por su antecesor al ocupar éste un rango eclesiástico superior y por otro lado, ante la importante labor patrimonial que éste desarrolló durante su mandato. Por lo tanto, Siuri, con su patrocinio realizado en el templo catedralicio y en la ciudad a base de la intervención en iglesias parroquiales, conventos y colegios, intentó igualar su paso por la diócesis al de fray Pedro de Salazar ${ }^{22}$.

${ }^{21}$ M. NIETO CUMPLIDO, Op.cit., pp. 382-390; B. MENOR BORREGO, El templo parroquial de El Sagrario de la Santa Iglesia Catedral de Córdoba, Córdoba, 2003.

${ }^{22}$ Obispo de Córdoba a comienzos del siglo XVIII y Cardenal de la Santa Cruz de Jerusalén por mandato de Inocencio XI desarrolló una gran labor de patrocinio en la catedral y en la ciudad convirtiéndose en un paradigma de la sociedad estamental del siglo XVIII. Auspició notables obras en ella entre las que destaca el Hospital de Agudos, actualmente Facultad de Filosofía y Letras, el convento de la Merced y dentro del templo
Queda patente que los templos catedralicios a lo largo de la historia han sido los lugares idóneos donde plasmar la huella de las autoridades. La catedral de Córdoba, y concretamente esta intervención, es un ejemplo de ello, ya que aprovechando la necesidad de rehabilitar las techumbres todos los prelados que ocuparon la silla episcopal durante el desarrollo de las obras participaron en ellas. Sin embargo, la plena transformación de la catedral se la atribuyeron de manera conjunta el cabildo catedralicio y Marcelino Siuri.

La descrita intervención permaneció intacta hasta que en 1860, bajo el episcopado de Juan Alfonso de Albuquerque y con la colaboración del canónigo lectoral Vicente Cándido López, se procedió a eliminar la cal que cubría los arcos y se repuso sobre el enlucido la bicromía de las dovelas. En este caso observamos nuevamente la misma manera de actuar pero con una nueva mentalidad y una nueva concepción estética. A comienzos del siglo XIX se rechazan todos los valores estéticos del barroco y se busca la pureza de las formas, recuperando la originalidad de las construcciones a través de la eliminación de los añadidos históricos que la envolvieron de manera progresiva. A partir de entonces comienza un nuevo período de transformación espacial del templo basado en la eliminación gradual de todos los vestigios de estética barroca. A finales del siglo XIX, Ricardo Velázquez Bosco eliminó las bóvedas correspondientes a las naves extremas de la zona oriental de la ampliación de Al-Hakam II y finalmente, entre 1975 y 1976, bajo la dirección del ar-

catedralicio la capilla de santa Teresa. Siuri intervino en la reforma y transformación de la iglesia parroquial de san Andrés, en la de san Nicolás y san Eulogio de la Ajerquía, en el convento de san Rafael, en el del Corpus Christi, en el del Cister, en el hospital de San Jacinto y en el colegio de Niñas Huérfanas de la Piedad. Además de otras intervenciones menores en muchos otros templos parroquiales y conventos de la ciudad y de la provincia. En definitiva, el comienzo del siglo XVIII en Córdoba estuvo protagonizado por ambos prelados ya que durante los dos mandatos se desarrollaron multitud de intervenciones que marcaron el devenir histórico del momento. 
quitecto Víctor Caballero Ungría, se derribaron las bóvedas barrocas restantes, a excepción de las ubicadas en la ampliación de la mezquita correspondiente a Almanzor, sustituyéndolas por la actual armadura de madera. Además, se picaron los enlucidos de los arcos hasta dejar a la vista las dovelas de piedra y ladrillos ${ }^{23}$. A partir de este momento la imagen de la catedral cambió, perdió la esencia barroca que la había inundando a comienzos del siglo XVIII y volvió a recuperar la identidad islámica debido a la influencia de las corrientes restauradoras de los siglos XIX y XX. Un claro ejemplo de ello fueron las arduas tareas de reconstrucción y reposición de la armadura correspondiente a las naves de la antigua maqsura para las que se tomaron como modelo las indicaciones de Al-Idrisi y diversos fragmentos de vigas y tableros originales que se encontraron sobre las capillas de san Pedro y san Lorenzo y también en el lateral sur de la Capilla Real ${ }^{24}$.

\section{CAPILLA DEL BAPTISTERIO}

A comienzos del siglo XVII la catedral de Córdoba careció de baptisterio a pesar de tener un espacio destinado para ello ${ }^{25}$. En 1679 el obispo fray Alonso de Salizanes solicitó al cabildo catedralicio que el lugar que has-

${ }^{23}$ M. NIETO CUMPLIDO, Op.cit., pp. 113, 115 y 249.

${ }^{24}$ Ibídem, pp. 249-254; véase al respecto M. NIETO CUMPLIDO, "El artesonado de la mezquita de Córdoba", Patrimonio Cultural y Derecho, no 10, 2006, pp. 177192.

25 Según las referencias documentales el templo catedralicio permaneció 85 años sin capilla destinada para el bautismo, desde la finalización de las obras de la capilla del Sagrario hasta el año 1679, en el que por intervención del obispo fray Alonso de Salizanes se solicitó trasladar la pila bautismal. Esto nos indica que la capilla elegida por el referido obispo no tenía ninguna función a pesar de ubicarse en ella la pila bautismal, recurriendo al cabildo catedralicio para que ésta fuese trasladada hasta el muro oriental del edificio y se reutilizara la capilla de san Matías, que estaba en mal estado de conservación, como necesaria capilla del baptisterio. Dichas referencias están recogidas en T. MORENO, Relación de las cosas notables del templo, material de la Santa Iglesia de Córdoba. Córdoba, 1744, p. 309. ta entonces albergaba la pila bautismal pasara bajo su custodia pudiendo transformarlo en su capilla privada con la advocación de Nuestra Señora de la Concepción, y además que la pila se trasladara hacia la capilla de santa Marina y san Matías al encontrarse ésta abandonada, pudiendo de este modo reutilizar dicho $\operatorname{lugar}^{26}$. Desde el traslado y la puesta en valor de la capilla como espacio bautismal no se desarrollaron labores de mantenimiento en la misma, lo que ocasionó su deterioro progre$\operatorname{sivo}^{27}$. Esta fue la causa que fundamentó su transformación a comienzos del siglo XVIII, al igual que la construcción del nuevo sistema de cubrimiento del templo. Sin embargo, es obvia la existencia de otras cuestiones que conllevaron la rehabilitación del baptisterio y que iremos analizando de manera detenida.

Las obras de las cubiertas habían sido concluidas recientemente y supusieron una

${ }^{26}$ J. GÓMEZ BRAVO, Op.cit., p. 717; La capilla del baptisterio actualmente se ubica en el espacio que ocupó la capilla de santa Marina, fundada por el tesorero de la catedral, Gutier Gonzálvez, el 25 de octubre de 1262. Dicha capilla fue reducida a un simple altar hacia 1454, permaneciendo de este modo hasta la mitad del siglo XVI. El 16 de marzo de 1411 el arcediano don Gonzalo Venegas y el canónigo Alfonso Fernández de Vargas, procuradores del cabildo, entregaron a Fernán Gómez de Herrera, mayordomo del condestable don Ruy López Dávalos y a su mujer Leonor López, un solar para construir una capilla concebida como lugar de enterramiento en la catedral dedicada a san Matías, teniendo un plazo de 3 años para su construcción. Con toda seguridad, el espacio destinado para esta capilla fue el mismo en el que anteriormente se situaba la capilla de santa Marina. Por todo ello, se puede apreciar actualmente una cartela en la que se indica que dicha capilla recibe el nombre de santa Marina, san Matías y Baptisterio. M. NIETO CUMPLIDO, La catedral..., p. 411; L. M. RAMÍREZ Y DE LAS CASAS DEZA, Op.cit., p. 106.

${ }^{27}$ Este hecho queda corroborado al no existir ninguna mención durante este largo período de tiempo a la capilla bautismal y por consiguiente la inexistencia de referencias a intervenciones en ella. Ello podría estar ocasionado por la falta de utilidad de este espacio, ya que desde la construcción del Sagrario, las celebraciones bautismales se comenzaron a desarrollar dentro de este templo parroquial ubicado en el interior del edificio catedralicio, cayendo en el olvido la capilla bautismal del mismo. 
transformación que adaptaba el espacio a las corrientes estéticas del momento. Siuri apoyó la conclusión de las obras con un aporte económico que quedó plasmado sólo en los registros documentales, ya que su participación no supuso ningún cambio en el proyecto. Por ello, su intervención en la transformación del baptisterio cobró mayor importancia, ya que aprovechando el deteriorado estado de conservación de la capilla, intercedió ante el cabildo catedralicio a fin de crear un nuevo espacio acorde a la estética barroca del templo, y a su vez publicitó su imagen ubicando en el retablo su escudo episcopal. De este modo, garantizó su huella en el edificio y su perdurabilidad. En este caso, el patrocinio del obispo Siuri no se limitó a un aporte económico, sino que, a lo largo del proceso de rehabilitación del espacio, estableció unas directrices que obedecían principalmente a sus propios intereses.

Las obras comenzaron el 8 de agosto de 1722 , cuando se obtuvo la licencia del cabildo catedralicio para abrir una ventana que permitiera el acceso a la luz natural ${ }^{28}$. Dado que las referencias documentales a las obras indican que la intervención de Siuri fue en 1723, podemos deducir que poco tiempo después, $\mathrm{y}$ aprovechando las obras de apertura de la ventana, el obispo decidió transformar la capilla que pasó a estar definida por dos elementos cruciales: la pila y el retablo fingido.

La pila sufrió la modificación de su taza original al introducir en ella una concha de alabastro que la compartimentó en dos espacios (Fig.4), una zona destinada para albergar el agua bendita y la otra para recibir el agua que rociaba a los infantes. Dicha medida fue llevada a cabo según una disposición que el Papa Benedicto XIII incluyó en su todavía vigente Memoriale Rituum (tit. VI, cap. II, § 5, 9) como medida de pulcritud ya que el agua bendita debía ser conservada durante 10 meses consecutivos ${ }^{29}$. A su vez, Siuri determinó

${ }^{28}$ ACCO, Actas Capitulares, libro 72, año 1719-1724.

${ }^{29}$ T. MORENO, Op.cit., p. 310; Enciclopedia católica online, consultado el 16 de enero del 2015. URL: http://ec.aciprensa.com/wiki/Pila_bautismal http:// que la pila debía contar con un cubrimiento. Esta decisión se basó en el libro XII, capítulo LXII de Ambrosio de Morales $^{30}$. La cubierta es una estructura piramidal de madera tallada, coronada por una figura alegórica de la $\mathrm{fe}^{31}$. Se representa como una imagen femenina de rasgos aniñados, portando un cáliz en la mano derecha y posee vestimentas voluminosas guarnecidas por un falso estofado a base de elementos vegetales policromados con colores benéficos: blanco, rojo y verde ${ }^{32}$.

ec.aciprensa.com/wiki/Pila_bautismal; El Memoriale Rituum fue publicado por primera vez por orden del Papa Benedicto XIII en 1725, como un "recordatorio de los ritos para llevar a cabo en pequeñas iglesias parroquiales algunas de las funciones principales del año".

${ }^{30}$ A. DE MORALES, Crónica general de España, Alcalá de Henares, 1577, pp. 194 v.-195 v. En él se recoge la celebración del decimoséptimo Concilio de Toledo. Fue el Concilio de obispos del reino de los visigodos en España celebrado en Toledo en el año 694. Insatisfecho el rey Égica con las decisiones del concilio anterior contra los judíos y de la falta de entusiasmo de los obispos, convocó un nuevo concilio iniciado el 9 de noviembre en la iglesia de santa Leocadia en el que designar una serie de acuerdos y directrices comunes para proceder todos de manera conjunta y reprimir las audacias del pueblo judío en África. En él se establecieron diversos cánones entre los que se encuentra el que indica que el baptisterio debía permanecer cerrado a comienzos de la cuaresma. El canon comienza de la siguiente forma: "Aunque al principio de la cuaresma cesa la administración general del bautismo; sin embargo, el órden eclesiástico pide de necesidad que en el mismo día se cierren las puertas del bautisterio por mano del pontífice, y se sellen con su anillo, y que por ningún pretesto se abran hasta la solemnidad de la Cena del Señor; para que por este sello de los pontífices se demuestre en todo el orbe que en estos días no es lícito administrar el bautismo ni dar la santificación sin una apremiante necesidad; y en el día de la resurrección del señor vuelvan á abrirse del mismo modo que se cerraron, en cuyo día se abrió paso al hombre para la vida; para que toda vez que fue consepultado resucite con él en la gloria de Dios (...)" J. TEJADA Y RAMIRO, Colección de cánones y de todos los concilios de la iglesia de España y de América: en latín y castellano, con notas e ilustraciones. Tomo II, Madrid, 1859, pp. 589 y 597; T. MORENO, Op.cit., pp. 312-313.

${ }^{31} \mathrm{La}$ fe, la esperanza y la caridad son las tres virtudes teologales que se alcanzan tras el sacramento del bautismo. Aparecen citadas en el Nuevo Testamento y concretamente en la Primera Carta del Apóstol San Pablo a los Corintios, 13,1-13.

${ }^{32}$ La fe suele estar representada iconográficamente con una gran cruz sujetada en su mano izquierda y la 


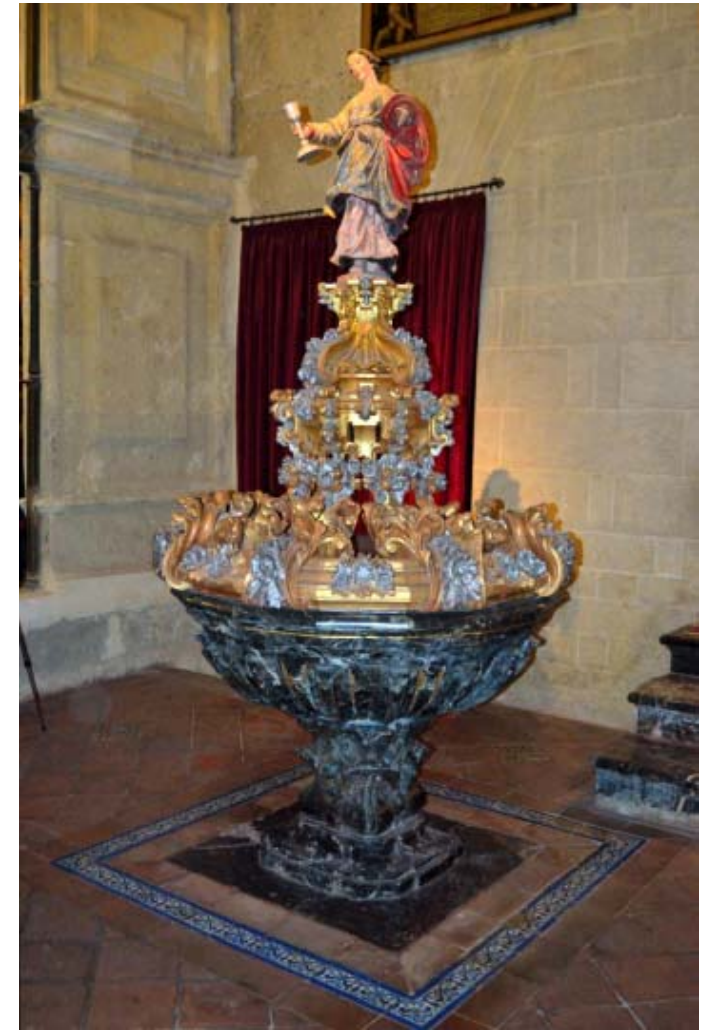

- Fig. 4. Pila bautismal de jaspe negro y cubierta de madera tallada ubicada en la capilla del baptisterio de la catedral de Córdoba. Foto del autor.

El otro elemento que configura la capilla es un retablo fingido realizado por Pedro Moreno a base de pintura al fresco y al temple ${ }^{33}$. El retablo tiene una estructura y una perspectiva estudiada para otorgar monumentalidad a pesar de ubicarse en un espacio reducido ${ }^{34}$.

derecha en el pecho, simbolizando que en el corazón se contiene la viva y verdadera fe. También puede aparecer con un libro abierto simbolizando las Sagradas Escrituras, con un corazón en llamas, con un cirio encendido, con maná, o con un cáliz, tal y como la podemos apreciar en este caso, aludiendo a la Eucaristía. A su vez, puede portar una iglesia sobre su cabeza o una tiara. La actitud en la que se puede representar es mostrando los atributos que porta o pisoteando la herejía. L, RÉAU, Iconografía del arte cristiano. Introducción general, Barcelona, 2008, pp. 92 y 225-227.

${ }^{33} \mathrm{ACCO}$, Inventario obras-restauraciones, caja 20, proyecto $\mathrm{n}^{\mathrm{o}} 135$.

${ }^{34}$ Los retablos fingidos comienzan a tener un gran desarrollo durante el siglo XVIII, a la vez que la escenografía alcanza un mayor desarrollo compositivo creando espacios fingidos de gran complejidad que acompa-
Los retablos fingidos surgen ante la necesidad de crear conjuntos ornamentales que magnifiquen los espacios y que a su vez no conlleven labores estructurales significativas ni costes económicos elevados, y todo ello queda de manifiesto en el baptisterio catedralicio.

Estructuralmente crea un efecto óptico que transforma uno de sus paramentos en una superficie cóncava. De este modo rompe la cuadratura del espacio y obtiene una sensación espacial de mayor amplitud. Está configurado por un basamento, un cuerpo central y un ático, todo ello delimitado por tres calles. El efecto cóncavo es reforzado por el retranqueo que define al basamento y al arquitrabe, la superposición en diversos planos de las columnas y la semicúpula que corona la composición. Todo ello es logrado a partir de un complejo análisis de las perspectivas y de las luces y sombras que permite crear una estructura monumental con gran volumetría en una superficie bidimensional. Del mismo modo, se fingen los materiales que lo configuran recurriendo al trampantojo a fin de imitar la utilización de mármoles y jaspes. La simulación de dichos materiales en la estructura del retablo posiblemente fue dada ante la recurrente utilización de los mismos en muchos conjuntos retablisticos del templo catedralicio, destacando el retablo mayor, ante el gran virtuosismo estético que se alcanzó con ellos y que definieron el comienzo del siglo XVIII de la mano del maestro Francisco Hurtado Izquierdo y ante la intencionalidad de Siuri de emular la labor de patrocinio desarrollada por su antecesor el cardenal Salazar, en cuya capilla, dedicada a santa Teresa, convergen todos los aspectos indicados ${ }^{35}$. A su vez, la tipología estructural que lo define no muestra nada excepcional, sin embargo, analizando las producciones coetáneas y los maes-

ñaban las obras de teatro y ópera. J. J. MARTíN GONZÁLEZ, El retablo barroco en España, Madrid, 1993, p. 15.

${ }^{35}$ Para profundizar en aspectos biográficos del arquitecto y retablista consultar M. A. RAYA RAYA, El retablo en Córdoba durante los siglos XVII y XVIII, Córdoba, 1980, p. 105; El estudio detallado sobre la capilla referida se puede consultar en M. NIETO CUMPLIDO, $\mathrm{L} a$ catedral..., pp. 370-373. 

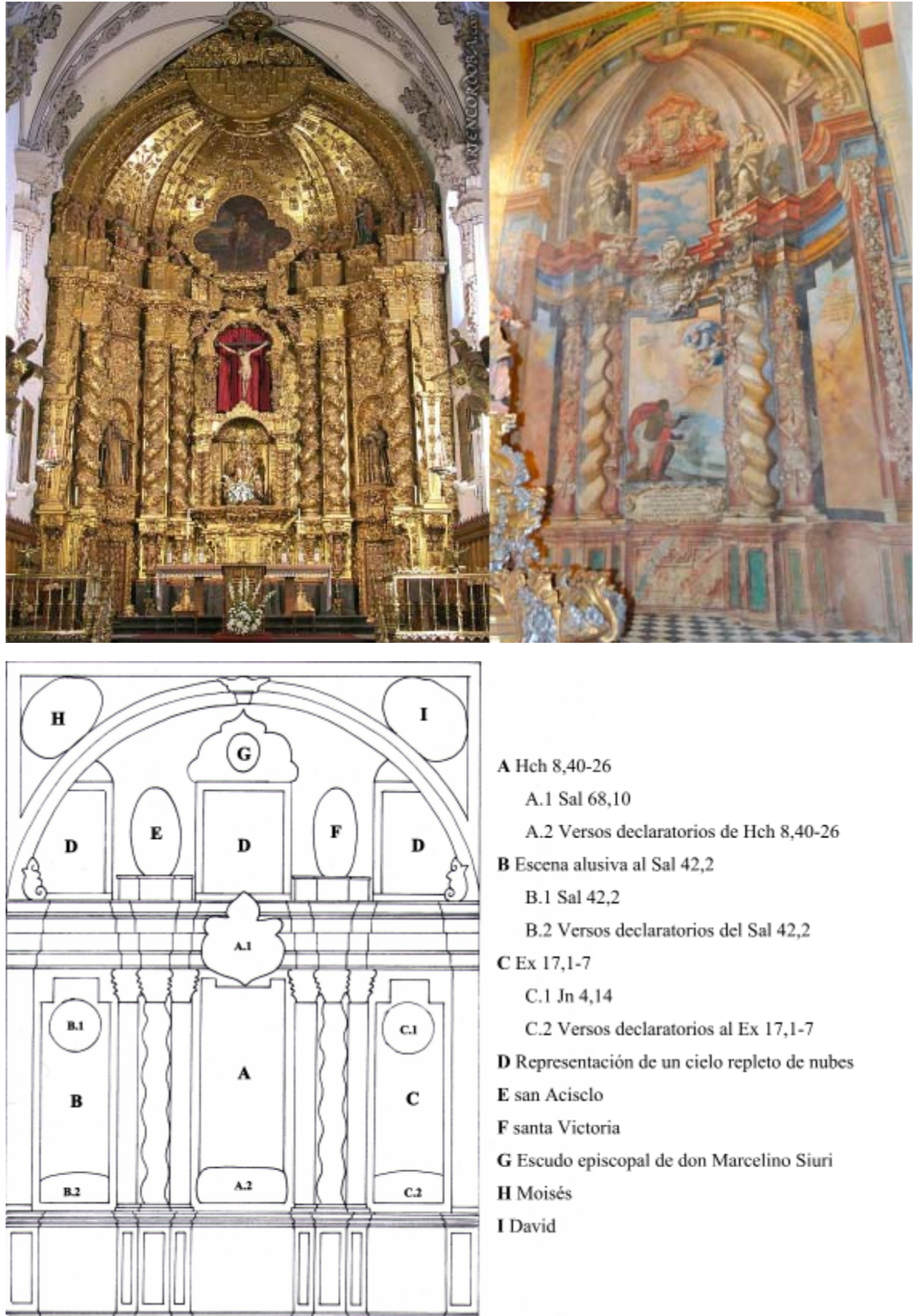

A Hch $8,40-26$

A. 1 Sal 68,10

A. 2 Versos declaratorios de Hch 8,40-26

B Escena alusiva al Sal 42,2

B. 1 Sal 42,2

B. 2 Versos declaratorios del Sal 42,2

C Ex 17,1-7

C. 1 Jn 4,14

C. 2 Versos declaratorios al Ex 17,1-7

D Representación de un cielo repleto de nubes

E san Acisclo

F santa Victoria

G Escudo episcopal de don Marcelino Siuri

H Moisés

I David
- Fig. 5. Comparativa estructural de ambos retablos. A la izquierda retablo del antiguo convento de San Pedro el Real y a la derecha retablo fingido del baptisterio de la catedral de Córdoba. http:// www.artencordoba.com y foto del autor.
- Fig. 6. Esquema del retablo fingido del baptisterio de la catedral de Córdoba. Dibujo del autor. tros que por entonces trabajaron de manera constante en la catedral, se puede deducir que muestra una influencia compositiva del retablo del antiguo convento de San Pedro el Real, realizado por Teodosio Sánchez de Rueda en 1720 (Fig.5) ${ }^{36}$. No existe documentación

${ }^{36}$ El estudio detallado de la vida y obra de dicho retablísta lo realiza M. A. RAYA RAYA, El retablo barroco cordobés. Córdoba, 1987, pp. 64-70; La disposición de ambos retablos es la misma, la utilización de los soportes es similar e incluso se imita la distribución de las columnas en diversos planos y se recurre al mismo tipo de que confirme la relación de influencias entre ambas producciones, pero según lo expuesto se podría pensar que el pintor Pedro Moreno siguió las directrices de Siuri dirigidas a imitar las producciones de los artistas coetáneos que fueron requeridos por su antecesor en la

capiteles. A su vez, el ático de ambos ejemplos está protagonizado por una semicúpula. En definitiva, estamos convencidos que estructuralmente el citado conjunto retablístico de la actual iglesia de San Francisco y San Eulogio sirvió de modelo para la composición general del único retablo fingido de la catedral de Córdoba. 
silla episcopal, a fin de continuar con la nueva concepción estética que éste dio comienzo.

La composición estructural analizada alberga una configuración iconográfica basada en el sacramento del bautismo, de ahí las menciones constantes al agua y la lluvia. Está formado por ángeles, apóstoles, profetas $\mathrm{y}$ virtudes, acompañados con versos aportados por el padre don Juan de Santiago de la Compañía de Jesús (Fig. 6) ${ }^{37}$. Además de la alusión al bautismo, el retablo alberga otra interpretación a través de la lluvia. Está en relación con la complicada situación que atravesaba la economía cordobesa durante los primeros años del episcopado de Siuri, provocada por la ausencia de lluvias que imposibilitó obtener cosechas. De manera progresiva se comentarán ambas interpretaciones e iremos poniéndolas en relación con el contexto social de la ciudad.

Iconográficamente, el retablo está dividido en dos sectores; el cuerpo central y el ático $^{38}$. El primero está configurado por tres pinturas alusivas al sacramento del bautismo. La escena principal representa a Dios rociando lluvia sobre el cuerpo postrado de un etíope, (Hechos de los Apóstoles 8,40$26)^{39}$. Se completa la composición con una filacteria donde se recoge: Lavabis me et super nivem dealbabor, (Salmo 51), y unos versos

${ }^{37}$ M. NIETO CUMPLIDO, La catedral..., p. 412; T, MORENO, Op.cit., pp. 309-310.

${ }^{38}$ En la actualidad el retablo conserva solo la pintura central del cuerpo principal, ya que de los laterales se conservan escasos restos, entre los que destaca un angelote con una cartela. No obstante, una descripción de Tomás Moreno ha permitido conocer cuales eran las composiciones laterales. Es por ello que la narración de ambas composiciones se desarrolla en pasado.

${ }^{39}$ En él se narra el proceso a través del que uno de los personajes recibió el bautismo tras comprender la profecía de Isaías. La figura del africano aparece semidesnuda, con un paño blanco, símbolo de pureza y puesto en relación con los catecúmenos y otro rojo, alusivo a la Eucaristía. Ambos colores y su simbología cobran sentido en la escena representada ya que, una vez es comprendido el pasaje de Isaías, el etíope se encuentra en disposición de recibir el bautismo al igual que los catecúmenos tras su instrucción en la doctrina católica. referentes a la escena ${ }^{40}$. La representación del lateral izquierdo albergaba una cierva bebiendo agua de una fuente y se acompañaba en la parte superior con Quemadmodum desiderat cerous ad fontes aquarum ita, (Salmo 42-2), y en la inferior con unos versos ${ }^{41}$. La ubicada en el lateral derecho cobijaba una figuración de la Roca de Horeb, (Éxodo 17,17), se completaba con Aquam, quam ego dabo fiet in eo fons aquae salientis in vitam eternam, (Evangelio de San Juan 4,14) y, al igual que las dos escenas descritas, con unos versos relativos a la representación ${ }^{42}$. Las tres escenas que configuran el cuerpo central del retablo aluden directamente al bautismo y a su vez, cada una de ellas deja patente una virtud; es decir, la escena central alude a la exaltación de la fe, la ubicada en el lateral izquierdo se decanta por la esperanza y la del derecho por la caridad. Cada escena está presidida

\footnotetext{
${ }^{40}$ La traducción del versículo del salmo 51 es: "Lávame y quedaré más blanco que la nieve". A partir de él surgirá la antífona procesional Asperges me entonada por el coro mientras se rocía con agua bendita la mesa del altar cuya composición es la siguiente: Asperges me Domine hyssopo, et mundabor:/ lavabis me et super nivem dealbabor./ Miserere mei Deus, secundum magnam misericordiam tuam./ Gloria patri et filo et spiritui sancto Sicut erat in principio et nunc et Semper et insecula seculorum amen. Los versos que acompañaban a la escena son: "Baja raudal divino/ agua bellisima, agua misteriosa,/ agua que amante Dios previno, / llubia por tantos titulos graciosa/ Ben, que mi tez oscura/ espera de su gracia la hermosura".

${ }^{41}$ La traducción del salmo 42-2 es: "Como ansía la cierva corrientes de agua, así mi alma te ansía, oh Dios". Los versos alusivos a la escena son: "Qual ciervo empozoñado/ busca en las aguas su remedio y vida/ asi por el pecado/ primero el alma moralmente herida/ busca en las aguas su remedio y vida/ asi por el pecado/ primero el alma mortalmente herida/ llegándose a esta fuente/ halla remedio y vida eternamente".

${ }^{42}$ El Éxodo 17, 1-7 narra la intervención de Dios a través de Moisés para colmar la sed de los israelitas durante su camino por el desierto; la traducción del referido pasaje es: “Quien beba del agua que yo le daré no tendrá sed jamás, pues el agua que yo le daré se convertirá dentro de él en manantial que brota dando vida eterna"; los versos alusivos a la composición son: “O Fuente/, O agua!. O Salto!/ milagros de la gracia! ¿Quién creyera/ que a termino tan alto/ el agua suba de tan baja esfera/ llevandose hasta el cielo/ quanto unido a esta piedra halla en el suelo".
} 
por el bautismo, pero cada una alude a una virtud teologal.

El ático muestra un cambio respecto a la temática compositiva, ya que se hacen alusiones directas a la ciudad de Córdoba. En él se ubican tres ventanales desde los que se aprecia un cielo abierto y entre ellos se sitúan dos figuras escultóricas. De nuevo se recurre a la técnica del trampantojo a fin de crear ilusiones ópticas que hagan creer que las figuras representadas y los ventanales tienen tres dimensiones. No obstante, se trata de pinturas que representan ventanas y a los dos patronos de la ciudad; san Acisclo y santa Victoria. Ambos se distinguen por sus atributos: la palma como mártires, san Acisclo por la espada y santa Victoria con la flecha. A pesar de ser figuraciones escultóricas, se concibieron como elementos estructurales del retablo cuya importancia radica más en la simbología que en su propia configuración, de ahí que no aparezcan policromadas. La ubicación de ambas figuras en la parte alta del retablo y rodeadas por ventanales abiertos hacia el cielo nos muestra la segunda interpretación del retablo. A la llegada de Siuri al poder episcopal se encontró una ciudad que atravesaba años complicados respecto a las malas cosechas, dadas las continuadas sequías $^{43}$. Siuri dispuso repartir entre la población cantidades ingentes de trigo a fin de solventar la trágica situación ${ }^{44}$. Aprovechando que las obras del retablo se estaban realizando, en él quedaron reflejadas las acciones llevadas a cabo por Siuri. De este modo, los ventanales abiertos hacia un cielo despejado y cobijados por los patronos de la ciudad aluden a los prolongados períodos de sequía por los que atravesaba la ciudad y los problemas

${ }^{43}$ La referida situación se fue desarrollando desde año 1712. En el invierno de 1715 la situación empeoró imposibilitando la recogida de la semillas que se habían sembrado. Los años de 1717 y 1718 la sequía se tornó en continuas inundaciones que impidieron la recogida de fruto empeorando aún más la complicada situación. L. M. RAMÍREZ Y DE LAS CASAS DEZA, Anales de la ciudad de Córdoba (1236-1850). Córdoba, 1948, p. 189.

${ }^{44}$ J. GÓMEZ BRAVO, Op.cit., p, 771; F. SEGUER, Op.cit., p, 116. que conllevaron. A ello se debe añadir la ubicación del escudo episcopal de Siuri coronando el ventanal central (Fig.7) ${ }^{45}$. Y debajo de él la siguiente inscripción: Pluviam voluntariam segrevavis Deus Hereditati tuae, (Salmo 68,10) ${ }^{46}$. Todos los elementos indicados convergen para configurar el ático como un escenario publicitario en el que se refleja la complicada situación de la ciudad y la intercesión de Siuri a fin de paliarla ubicando su insignia en un lugar estratégico.

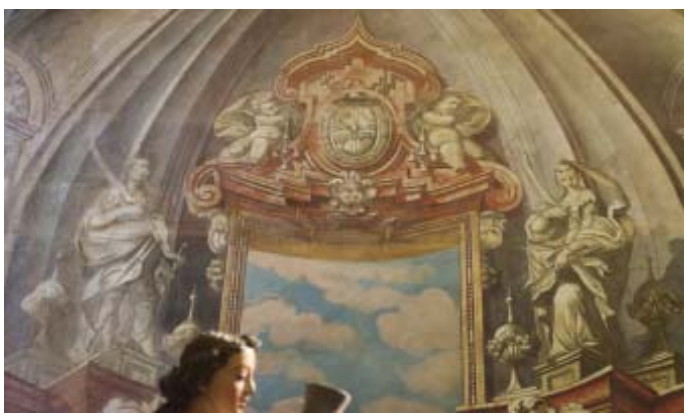

- Fig. 7. Ático del retablo de la capilla del baptisterio de la catedral de Córdoba. A la izquierda san Acisclo, a la derecha santa Victoria y en el centro el escudo episcopal de don Marcelino Siuri. Foto del autor.

Para concluir con el programa iconográfico, cobijando los dos ángulos superiores se sitúa a la izquierda Moisés y a la derecha David (Fig. 8). Este último se acompaña con una filacteria en la que se puede leer et á peccáto meo munda me, (Salmo 51) ${ }^{47}$.

${ }^{45}$ El escudo episcopal de Siuri está formado a partir de un águila ubicada en su parte central y sus cuatro cuarteles se definen con un león, un brazo armado con una espada, un árbol y un castillo. J. M. ÓRTIZ JUAREZ, "La obra en Córdoba del ilicitano don Marcelino Siuri, obispo y escritor", Revista del Instituto de Estudios Alicantinos, no 12, II época, 1974 p. 43. Para el estudio en profundidad de las armerías en el templo catedralicio cordobés se debe consultar el trabajo de J. A. MOLINERO MERCHÁN, La mezquita-catedral de Córdoba: símbolos de poder. Estudio histórico-artístico a través de sus armerías, Córdoba, 2005.

46 “Una lluvia generosa derramaste, Dios, tú aliviaste tu heredad extenuada".

47 "y límpiame de mi pecado". Se trata de un salmo penitencial en cuya composición se suplica el perdón de todos los pecados cometidos. 


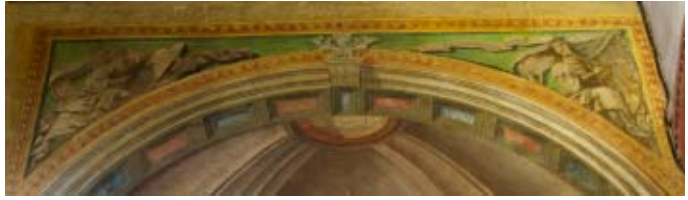

- Fig. 8. Detalle de la parte superior del retablo de la capilla del baptisterio de la catedral de Córdoba. A la izquierda Moisés y a la derecha David. Foto del autor.

El retablo se ha convertido en el eje vertebrador del baptisterio catedralicio. Su creación conllevó la transformación espacial del recinto engrandeciéndolo a través de una compleja estructura fingida que a base de efectos de luz y sombra y estudiadas perspectivas ha originado un monumental aparato retablístico. A su vez, alberga un programa iconográfico relacionado directamente con el sacramento del bautismo donde el agua y la lluvia cobran especial interés, siendo ésta última la protagonista del ático. En el retablo es en donde convergen todas las causas que fundamentaron la intervención en este espacio. Por un lado, el mal estado de conservación de la capilla; por otro lado, la adaptación de ese espacio a las nuevas corrientes estéticas del momento y la unión con la nueva concepción espacial que el templo había adquirido con las techumbres abovedadas; y por último, la intención del prelado de dejar una huella visible en el templo catedralicio. Es por ello que en la zona alta de la composición se sitúa su escudo de armas, que reivindica la autoría de este nuevo espacio y su intervención paliativa en la complicada situación de la sociedad cordobesa.

La creación de este tipo de retablos es muy escasa en todo el territorio español, no obstante, podemos encontrar ejemplos en Valladolid, del pintor Diego Valentín Díaz; uno realizado para la iglesia del Colegio de Niñas Huérfanas y otro para la iglesia de San Miguel. En Toledo se localizan el retablo mayor de la iglesia de los Jesuitas y el retablo de la ermita de la Puebla de Montalbán, ambos pintados por los hermanos Luis y Alejandro González Velázquez en torno a 1741 y $1742^{48}$.

${ }^{48}$ J. J. MARTÍN GONZÁLEZ, El retablo..., p. 15.

\section{CONCLUSIÓN}

A lo largo del presente estudio se ha mostrado la evolución estética que el templo catedralicio cordobés sufrió a comienzos del siglo XVIII. Se le otorgó una concepción espacial nueva acorde a las corrientes artísticas, a las formas de pensamiento, a los cambios de la liturgia y a los intereses de obispos y cabildo catedralicio que se fueron imponiendo con la llegada del barroco. El nuevo sistema de cubierta y la novedosa capilla bautismal fueron la última gran transformación material y visual a la que el templo se sometió a fin de cristianizar el espacio. La catedral de Córdoba es única dado su origen y por lo tanto a lo largo de su existencia las diversas etapas históricas han realizado cambios en su morfología y en su exornación a fin de adaptarla a las necesidades que requería su nueva funcionalidad, superponiendo esas modificaciones a los elementos originales. De este modo los vestigios islámicos del edificio se ocultaron de manera progresiva. La conclusión de las obras de abovedamiento cerró el ciclo de cristianización de todo el recinto ya que conllevó, junto con la construcción de la capilla mayor, el crucero y el coro, la metamorfosis más importante a la que el edificio había sido sometido, otorgando la sensación de una nueva construcción cobijada en la estructura heredada.

Don Marcelino Siuri fue el patrocinador en ambos casos, con la salvedad de que en el primero su aporte se limitó a una donación económica que saneó las arcas catedralicias y permitió concluir las obras con el aporte entregado por el cabildo. De este modo, tanto él como el cabildo se otorgaron el final de tan importante obra y todo lo que ello supuso para el edificio. Y en el caso de la capilla bautismal, Siuri realizó un aporte más importante, ya que no se limitó a entregar un caudal de dinero, sino que dispuso una serie de condiciones que el espacio requería y aprovechando la intervención, quiso plasmar su huella reivindicando su paso por la sede episcopal cordobesa, emulando la labor de patrocino desarrollada por el cardenal Salazar y reivindicando su propio patrocinio que actualmente se ha convertido en un unicum al no existir otro ejemplo de retablística fingida en la catedral. 